\title{
P2 Calcium Induced Intramitochondrial cAMP Signalling Enhances Aldosterone Secretion
}

\author{
Gergő Szanda*, Éva Wisniewski, Anikó Rajki, András Spät \\ Semmelweis University, Budapest, Hungary
}

\section{ABSTRACT}

Elevation of plasma $\left[\mathrm{K}^{+}\right]$and [angiotensin II] (Ang II), two major physiological stimuli of adrenal zona glomerulosa cells, increase aldosterone production by triggering cytosolic $\mathrm{Ca}^{2+}$ signalling. Cytosolic $\mathrm{Ca}^{2+}$ signals are accompanied by mitochondrial $\mathrm{Ca}^{2+}$ elevations which further strengthen this steroidogenic response. It has recently been recognized that such mitochondrial $\mathrm{Ca}^{2+}$ signals activate the mitochondrial soluble adenylyl cyclase (sAC) thus evoking intramitochondrial (matrix) cAMP elevations during $\mathrm{Ca}^{2+}$ signalling. We hypothesised that this $\mathrm{Ca}^{2+}$ induced mitochondrial cAMP production, too, contributes to the hypersecretion of aldosterone. Using human adrenocortical H295R cells we found that silencing of sAC decreased mitochondrial cAMP production and, at the same time, decelerated $\mathrm{Ca}^{2+}$ accumulation by the organelle. On the other hand, inhibition of the mitochondrial phosphodiesterase (PDE2A) intensified matrix cAMP production and accelerated mitochondrial $\mathrm{Ca}^{2+}$ uptake. More importantly, both pharmacological inhibition and knock-down of sAC mitigate AngII-induced aldosterone production. Finally, overexpression of wild-type sAC within the mitochondrial matrix increased mitochondrial cAMP formation, accelerated mitochondrial $\mathrm{Ca}^{2+}$ uptake and, most prominently, potentiated aldosterone production as compared to the enzymatically inactive mutant enzyme. Altogether, $\mathrm{Ca}^{2+}$-induced mitochondrial cAMP signalling supports aldosterone production by favouring additional $\mathrm{Ca}^{2+}$ influx into the organelle. This positive feed-back loop may expedite the hormonal response when immediate hypersecretion of mineralocorticoids is crucial for cardiovascular compensation (e.g. exsiccation, blood loss).
\end{abstract}

\section{REFERENCES}

[1] Katona D, Rajki A, Di Benedetto G, Pozzan T, Spät A. Calcium-dependent mitochondrial cAMP production enhances aldosterone secretion. Mol Cell Endocrinol 2015;412:196-204.

[2] Szanda G, Wisniewski É, Rajki A, Spät A. Mitochondrial cAMP exerts positive feedback on mitochondrial $\mathrm{Ca}^{2+}$ uptake via the recruitment of Epac1. J Cell Sci 2018;131:pii: jcs215178.

(C) 2019 Association for Research into Arterial Structure and Physiology. Publishing services by Atlantis Press International B.V. This is an open access article distributed under the CC BY-NC 4.0 license (http://creativecommons.org/licenses/by-nc/4.0/). 